\title{
Androgen-induced epigenetic modulations in the ovary
}

\author{
Irving Salinas ${ }^{1,2, *}$, Niharika Sinha ${ }^{1,3, *}$ and Aritro Sen ${ }^{1,3}$ \\ ${ }^{1}$ Reproductive and Developmental Sciences Program, Michigan State University, East Lansing, Michigan, USA \\ 2Department of Physiology, Michigan State University, East Lansing, Michigan, USA \\ ${ }^{3}$ Department of Animal Sciences, Michigan State University, East Lansing, Michigan, USA \\ Correspondence should be addressed to A Sen: aritros@msu.edu \\ *(I Salinas and N Sinha contributed equally to this work)
}

\begin{abstract}
In recent years, androgens have emerged as critical regulators of female reproduction and women's health in general. While high levels of androgens in women are associated with polycystic ovary syndrome (PCOS), recent evidence suggests that a certain amount of direct androgen action through androgen receptor is also essential for normal ovarian function. Moreover, prenatal androgen exposure has been reported to cause developmental reprogramming of the fetus that manifests into adult pathologies, supporting the Developmental Origins of Health and Disease (DOHaD) hypothesis. Therefore, it has become imperative to understand the underlying mechanism of androgen actions and its downstream effects under normal and pathophysiological conditions. Over the years, there has been a lot of studies on androgen receptor function as a transcriptional regulator in the nucleus as well as androgen-induced rapid extranuclear signaling. Conversely, new evidence suggests that androgen actions may also be mediated through epigenetic modulation involving both the nuclear and extra-nuclear androgen signaling. This review focuses on androgen-induced epigenetic modifications in female reproduction, specifically in the ovary, and discusses emerging concepts, latest perceptions, and highlight the areas that need further investigation.
\end{abstract}
Key Words
- androgens
- epigenetics
- female reproduction
- developmental programming
- histone modification
- DNA methylation

\section{Introduction}

Steroid hormones participate in almost every biological process operative in the mammalian system. However, the basic mechanisms involved in steroid hormone action are highly complicated and remain frustratingly unclear. To date, the physiological actions of steroids were thought to be mediated by the classical 'nuclear' and nonclassical 'membrane-initiated' steroid receptor signaling (Hammes \& Levin 2011, Levin \& Hammes 2016). It is now well-established that this crosstalk between steroidinduced extra-nuclear kinase signaling and intra-nuclear transcription is critical for many biological processes
(DeFranco 2002, Edwards 2005, Levin 2015, Levin \& Hammes 2016, Klinge 2018, Wilkenfeld et al. 2018). Interestingly, emerging evidence suggests that steroid hormones may also influence or alter gene expression through epigenetic modifications (Matsumoto et al. 2013). Control of gene expression occurs at different levels, one of which is the accessibility of genes and their controlling elements to the transcription machinery. Accessibility is regulated largely by the degree of chromatin compaction, which is modulated by several epigenetic markers (Kim \& Kaang 2017). This represents 
an independent avenue for steroids to coordinate gene regulation apart from the established pathways. Steroid receptors recruit several epigenetic modulators as an integral part of its transcription machinery and this has been extensively studied across species and cells/tissues (Heemers \& Tindall 2007, Thakur \& Paramanik 2009). However, the underlying mechanism(s) of how steroidinduced signaling causes epigenetic modifications and regulate downstream physiological functions are poorly understood. This review specifically focuses on androgeninduced epigenetic modifications with respect to ovarian function and overall female health. Here we discuss emerging concepts, latest perceptions, and highlight the areas that need further investigation.

Moreover, steroid-mediated events occurring during critical fetal developmental phases can alter the anatomy and physiology of steroid-targeted developing organs and systems (Solano \& Arck 2019). It is now widely accepted that an adverse peri-conceptional and/or intrauterine environment is associated with fetal epigenetic malprogramming causing a predisposition to chronic disorders later in life (Puttabyatappa \& Padmanabhan 2018). Epigenetics is thought to be by far the most likely mechanism by which intrauterine or postnatal steroid exposure affects the health and disease of the offspring. Therefore, we also discuss how prenatal and postnatal exposure to androgen results in epigenetic modulation and its manifestation of adult pathologies later in life.

\section{Androgen actions and female fertility}

In the last few years, there has been much focus on understanding androgen actions in women and androgens have emerged as a critical regulator of follicular development and female fertility (Prizant et al. 2014, Walters 2015) in both normal and pathophysiological conditions. In women, androgens are produced in the ovaries (Franks \& Hardy 2018), adrenal glands (Burger 2002), and fat cells (Cadagan et al. 2014) which exhibit its actions directly through androgen receptors (AR). In female reproduction, high levels of androgens have been considered detrimental to women's health leading to polycystic ovary syndrome (PCOS), hirsutism, and metabolic dysfunctions such as abdominal visceral adiposity, insulin resistance, and metabolic disturbances (London 1987, Escobar-Morreale et al. 2014). In contrast, global (Hu et al. 2004, Shiina et al. 2006, Walters et al. 2007) and granulosa cell-specific (Sen \& Hammes 2010, Walters et al. 2012) AR knockout female mouse models as well as clinical studies (Barad \& Gleicher 2005, Barad \& Gleicher 2006, Gleicher et al. 2013a,b) have established that direct androgen actions through AR in the ovary are critical for female fertility (Sen \& Hammes 2010, Sen et al. 2014). Disruption of androgen signaling negatively impacts female fertility by being associated with follicular dysfunction, premature ovarian failure (Hu et al. 2004, Shiina et al. 2006, Sen \& Hammes 2010, Wu et al. 2014, Ma et al. 2017b, Walters et al. 2018), and diminished ovarian reserve (Gleicher et al. 2013a). It is now believed that there exists a balance between the essentiality of androgen actions and its detrimental effects associated with high androgen levels. Understanding the mechanisms of androgen actions in regulating female reproduction has thus been the primary focus in the last couple of years (Prizant et al. 2014, Walters 2015, Walters et al. 2016, 2019, Franks \& Hardy 2018, Walters \& Handelsman 2018).

Moreover, in the last decade, several studies across species have shown that prenatal or perinatal androgen exposure has profound effects throughout an individual's lifespan (Abbott et al. 2002, Poston 2010, Padmanabhan et al. 2016). This concept of the fetal origin of adult diseases is now an area of intense research and has evolved into the field of Developmental Origins of Health and Disease (Barker 2007). Epigenetic programming appears to play a central role in prenatal or postnatal exposure to different steroid hormones and is one of the most common conditions for the 'fetal origins of adult disease'. It has been hypothesized that changes in the histone/DNA methylation/acetylation during critical periods of gestation is one of the mechanisms through which prenatal and postnatal exposure to androgens cause developmental programming (Padmanabhan et al. 2015). It is well-established across species that the neuroendocrine-reproductive axis, as well as metabolism, is significantly impacted by steroidal signaling during prenatal and postnatal periods (Gore 2008, Padmanabhan \& Veiga-Lopez 2013, Zambrano et al. 2014). Excess androgens disrupt gonadotropin-releasing hormone secretion, facilitating loss of the positive feedback response to estrogen by epigenetically reprogramming the refractoriness of the brain (Foecking et al. 2008). The epigenetic modulation by androgens on ovarian function can either be due to postnatal or prenatal exposure (Abbott et al. 2002, Nelson-DeGrave et al. 2004, Zhang et al. 2014, Walters 2015, Guo et al. 2019, Sinha et al. 2020). Misinterpretation of the de novo DNA methylation and active histone replacement during the oogenesis-specific developmental program has been reported in PCOS patients (Xu et al. 2010, Yu et al. 2017). 
Children born to mothers with PCOS or congenital adrenal hyperplasia, diseases characterized by excess androgens, are more susceptible to developing PCOS-like phenotypes, increased risk of metabolic dysfunctions, cardiovascular, and neoplastic diseases later in life (Abbott et al. 2002, 2005, 2008a,b, Padmanabhan et al. 2016). Given the importance of prenatal or perinatal androgen exposure in the fetal origin of adult diseases, here we discuss studies focused on determining the developmentally reprogrammed genes in the ovary and its downstream physiological effects caused by prenatal or perinatal androgen exposure.

\section{Androgen-induced epigenetic modulation in the ovary}

Androgen receptors transcriptionally regulate the expression of many genes either directly (Eder et al. 2001, Heemers \& Tindall 2007) through binding to ARE sites (androgen response element) on the promoter regions of genes or indirectly (Heinlein \& Chang 2002, Kang et al. 2004, Foradori et al. 2008) by modulating other transcriptional regulators via activation of different signaling pathways. Intriguingly, while androgens have been shown to play a major role in the hypothalamuspituitary-gonadal axis in females (Sen \& Hammes 2010, Walters et al. 2018), very few genes, so far, have been identified as direct AR targets. In the ovary, studies show that androgens may have a more global effect on gene expression which is primarily mediated through indirect rather than direct androgen actions (Ma et al. 2017a). Remodeling of the chromatin into an accessible conformation allowing recruitment of transcriptional elements is a key regulatory step of gene expression. Chromatin remodeling via histone modification is now considered a critical control step for transcription and a primary target of signal transduction. Post-translational modification (Badeaux \& Shi 2013) through kinasedependent phosphorylation (Cha et al. 2005, Wei et al. 2011, Yan et al. 2016) is one of the major mechanisms through which the activity of epigenetic enzymes can be regulated. Apart from histone modifications, androgen may regulate gene transcription through DNA methylation by interfering with the ability of transcriptional regulators to bind to the DNA. Conversely, the underlying mechanisms of how androgens regulate DNA methylation or histone modifications in the ovary and its effect on ovarian gene expression and downstream physiological processes, are poorly understood.

\section{Histone modifications}

Epigenetic modulation of gene expression is dependent partly on the dynamic balance of histone marks (methyl/demethyl and/or acetyl/deacetyl marks) on the enhancers and promoters. Enhancers are non-coding regions that are widely spread across the genome and have binding sites for transcription factors which in turn recruit co-activators. These enhancers are located either proximally or distally from the promoter region of genes in the genome and activate transcription by interacting with the promoter either by direct interaction between the enhancer-associated proteins and the promoter through looping of the DNA (Fig. 1A) or via tracking factors (like Pol II) down the DNA to connect to the promoter (Bulger \& Groudine 2011). Various histone marks in the enhancer regions determine if an enhancer region is active, primed, or poised. The dynamics between histone marks in the enhancer and/or promoter regions is mediated by regulating the expression and activity of various epigenetic enzymes (methylases/demethylases and/or acetylases/deacetylases) (Blum 2015, Hyun et al. 2017). Androgens through both the extra-nuclear and nuclear pathways can repress/activate the expression and activity of epigenetic enzymes resulting in an increase or decrease of the histone marks affecting the expression of
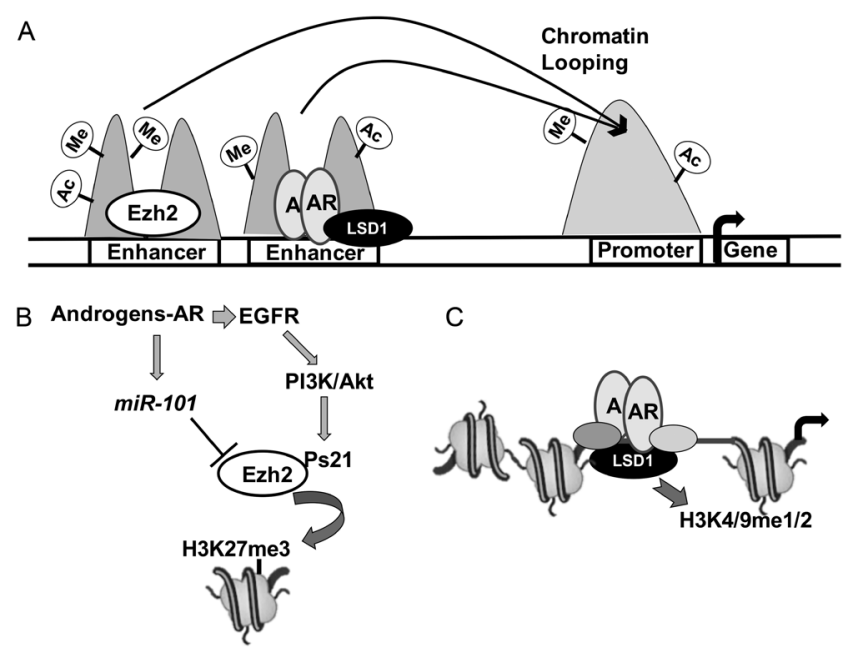

\section{Figure 1}

(A) Androgen-induced histone modifications occur in the distal enhancer and/or promoter regions of genes that in turn regulate gene expression (Stelloo et al. 2019). (B) Mechanism of androgen-induced histone modifications: androgens through activation PI3K/Akt pathway and induction of miR-101 expression inhibit the enzymatic activity and expression of $\mathrm{EZH} 2$, a histone methyltransferase responsible for trimethylation of lysine 27 on histone 3 (H3K27me3), a gene repressive mark. (C) Androgen receptors also recruit LSD1, a lysine-specific histone demethylase $1 \mathrm{~A}$ that demethylates mono- or di-methyl lysine 4 and 9 on histone 3 (H3K4/9me1/2). 
different genes that are crucial for ovarian function (Ma et al. 2017a) (discussed in detail in the section 'Postnatal/ in vitro androgen exposure'). However, this effect may vary based on the timing of androgen exposure. For example, prenatal androgen exposure may regulate a specific set of epigenetic modulators controlling precise epigenetic marks on the histone and/or DNA that affect the expression of a certain set of genes. In contrast, postnatal androgens may regulate a different set of genes by modulating other epigenetic marks. Also, the androgen-induced epigenetic modulation may be cellspecific within the ovary (Guo et al. 2019).

\section{Prenatal androgen exposure}

It has long been known (Abbott et al. 2006, Nugent et al. 2012, Padmanabhan \& Veiga-Lopez 2013, Walters 2015, Padmanabhan et al. 2016) that prenatal androgen exposure has a significant effect on ovarian function. However, only recently two studies (Guo et al. 2019, Sinha et al. 2020) investigated the histone modifications induced by prenatal androgen exposure in the androgenized sheep model. In one of the studies (Sinha et al. 2020), changes in different histone marks were determined in prenatally (from days 30 to 90 of gestation)-testosterone (T)-treated fetal (day 90) and adult (year 2) whole sheep ovaries. This study reported no epigenetic changes in D90 fetal ovaries, but prenatal testosterone treatment causes a significant increase in both gene repressive (H3K9me3-trimethylation of lysine 9 on histone 3 ) and gene activating (H3K27ac and H3K9ac - acetylation of lysine 27 and lysine 9 on histone 3) marks in adult (year 2) ovaries. This emphasizes that it is not imperative that the effect of prenatal androgen exposure on the epigenome occurs instantly in the fetus but can manifest even later in life. Other epigenetic marks determined in this study with no reported change were the gene repressive mark, H3K27me3 (trimethylation of lysine 9 on histone 3), and the gene activating mark, H3K4me3 (trimethylation of lysine 4 on histone 3). Intriguingly, RNA-sequencing data of ovarian gene expression revealed no change in the expression levels of any histonemodifying enzymes in adult (year 2) ovaries isolated from control and prenatal testosterone-treated sheep (Sinha et al. 2020). However, changes in mRNA or protein levels may not be enough to explain the downstream effects of these enzymes as the activity of these enzymes may be regulated at a post-translational level (Table 1).

In a second study (Guo et al. 2019), laser capture microscopy was used to compare the expression of various epigenetic enzymes and the level of histone marks in granulosa, theca and stromal cells isolated from adult (year 2) prenatally androgenized sheep. This study (Guo et al. 2019) reported that prenatal testosterone exposure (from days 30 to 90 of gestation) shows a trend or causes a significant increase/decrease in various epigenetic enzymes in a cell-specific manner within the ovary. For example (Guo et al. 2019), in granulosa cells, prenatal testosterone exposure increases histone methyltransferases; SUV39H1 that methylates Lys-9 of histone 3 (H3K9me3 - gene activating mark) and EZH2 that methylates Lys-27 of histone 3 (H3K27me3 - gene repressive mark); conversely, prenatal testosterone exposure decreases HDAC3 that deacetylates lysine residues on the N-terminal part of the core histones $(\mathrm{H} 2 \mathrm{~A}, \mathrm{H} 2 \mathrm{~B}, \mathrm{H} 3$, and $\mathrm{H} 4)$ resulting in epigenetic repression, and KDM1A that demethylates both Lys-4 (H3K4me - gene activating mark) and Lys-9 (H3K9me - gene repressive mark) of histone H3, thereby acting as a coactivator or a corepressor. In theca cells (Guo et al. 2019), it has been reported that prenatal testosterone exposure increases SMYD3 that specifically methylates Lys-4 of histone $\mathrm{H} 3$ inducing di- and tri-methylation (H3K4me2/me3 - gene activating mark) while decreasing HDAC3 (causes epigenetic repression) and KDM1A (can act as both coactivator/corepressor). Similarly, in stromal cells (Guo et al. 2019), prenatal testosterone exposure causes an increase in EZH2 (H3K27me3 - gene repressive mark) and a decrease in KDM1A. Moreover, in both granulosa and theca cells (Guo et al. 2019), there is an increase in $H D A C 1$ that catalyzes deacetylation on their substrates having lysine residues on the $\mathrm{N}$-terminal part of the core histones (H2A, H2B, H3, and H4). Notably, when the change in expression of the epigenetic enzymes was correlated with epigenetic marks, it was found that there was an increase in $\mathrm{H} 3 \mathrm{~K} 9 \mathrm{me} 3$ (gene repressive mark) levels in both granulosa and theca cells and an increase in H3K4me2 (gene activating mark) in theca and stromal cells (Table 1). These data (Guo et al. 2019) highlight two important insights: first, prenatal androgen exposure has differential effects on the epigenome in a cellspecific manner within the ovary. Second, changes in the expression of epigenetic enzymes do not always correlate with its activity and modulation of downstream epigenetic marks. This emphasizes that future studies are required to focus on correlating the expression and activity of an epigenetic enzyme with its specific downstream epigenetic marks with respect to prenatal testosterone treatment in the ovary. Importantly, further studies in other prenatal androgen exposure models like rodents and non-human primates are required to comprehend the effect of prenatal androgen exposure in the ovary across species. 
Table 1 Androgen-induced site-specific histone modifications in the ovary.

\begin{tabular}{|c|c|c|c|c|c|c|c|}
\hline \multirow[b]{2}{*}{ Species } & \multirow[b]{2}{*}{ Site of impact } & \multirow[b]{2}{*}{ Treatment } & \multicolumn{2}{|c|}{ Epigenetic enzymes } & \multirow[b]{2}{*}{ Epigenetic marks } & \multirow[b]{2}{*}{ Genes affected } & \multirow[b]{2}{*}{ References } \\
\hline & & & $\overline{U p}$ & Down & & & \\
\hline Human & Theca cells & In vitro & - & - & Histone acetylation & CYP11A and CYP17 & $\begin{array}{l}\text { Nelson-DeGrave } \\
\text { et al. } 2004\end{array}$ \\
\hline Sheep & Whole ovaries & Prenatal & - & - & $\begin{array}{l}\text { H3K9me3, H3K27me3, } \\
\text { H3K9ac, H3K27ac } \\
\text { and H3K4me3 }\end{array}$ & $\begin{array}{l}\text { SERPINA5, HSD3B1, } \\
\text { CTLA4, HSD17B14, } \\
\text { SPP1, OXTR, TNK1, } \\
\text { LIPG, HEY2, NDRG4 }\end{array}$ & Sinha et al. 2020 \\
\hline Sheep & Stromal cells & Prenatal & $\mathrm{EZH} 2$ & KDM1A & H3K4me2, H3K9me3 & - & Guo et al. 2019 \\
\hline Sheep & Theca cells & Prenatal & $\begin{array}{l}\text { HDAC1, } \\
\text { SMYD3, }\end{array}$ & $\begin{array}{l}\text { HDAC3, } \\
\text { KDM1A }\end{array}$ & H3K4me2, H3K9me3 & $\begin{array}{l}\text { CYP17, AR, ESR1, } \\
\text { ESR } 32, \text { LHCGR, FSHR, } \\
\text { INSR, ADIPOQ, PPARG }\end{array}$ & Guo et al. 2019 \\
\hline Sheep & Granulosa cells & Prenatal & $\begin{array}{l}\text { HDAC1, } \\
\text { SUV39H, } \\
\text { EZH2 }\end{array}$ & $\begin{array}{l}\text { HDAC3, } \\
\text { KDM1A }\end{array}$ & H3K4me2, H3K9me3 & $\begin{array}{l}\text { CYP19, CYP17, AR, } \\
\text { ESR1, ESR2, LHCGR, } \\
\text { FSHR, INSR, ADIPOQ, } \\
\text { PPARG, INHA, INHBA, } \\
\text { INHBB, FST, AMH }\end{array}$ & Guo et al. 2019 \\
\hline Mouse & Granulosa cells & In vitro & - & Ezh2 & H3K27me3 & Runx1 & Ma et al. $2017 a$ \\
\hline
\end{tabular}

\section{Postnatal/in vitro androgen exposure}

A recent study (Ma et al. 2017a) shows that androgens, in both human and mouse ovarian granulosa cells, through extra-nuclear signals can rapidly activate the PI3K/Akt pathway causing phosphorylation of the Polycomb group protein enhancer of zeste homolog 2 (EZH2), that is known to block the methyltransferase activity of EZH2 (Cha et al. 2005, Bredfeldt et al. 2010, Rojanasakul 2013). $\mathrm{EZH} 2$ is a histone methyltransferase (HMT) that promotes H3K27me3, a gene repressive mark. Furthermore, androgens through nuclear signaling cause the longterm inhibition of Ezh2 by increasing the expression of an anti-Ezh2 microRNA, miR-101 (Ma et al. 2017a). Figure $1 \mathrm{~A}$ demonstrates the proposed mechanism of androgeninduced regulation of EZH2 and H3K27me3 mark. In granulosa cells, this androgen-induced inhibition of EZH2 leading to modulation of H3K27me3 (Ma et al. 2017a) has been shown to play a critical role in the expression of luteinizing hormone-induced Runx1, a transcription factor critical for ovulation (Jo \& Curry 2006). Blocking of androgen-induced inhibition of Ezh2, in vivo, adversely affects Runx1 expression and subsequent ovulation in mice (Ma et al. 2017a). Based on these observations, it has been proposed that androgens may have a global effect on ovarian gene expression through modulation of EZH2 and H3K27me3 mark (Table 1). Further studies are needed to identify all the genes regulated by the androgeninduced decrease of the H3K27me3 mark and its effect on ovarian physiology. However, given the importance of EZH2 in epigenetic modulation of gene expression, it can be speculated that androgen-induced inhibition of EZH2 expression and activity has far-reaching effects on female reproduction and women's health. Interestingly, an EZH2 inhibitor, tazemetostat is currently in clinical trials for cancer patients and it has been reported that it can dramatically affect epigenetic programming in the fetal and adult oocyte (Prokopuk et al. 2018). Given that androgens inhibit EZH2 function and expression, it is highly possible that androgens may influence stem cell differentiation and other physiological processes through modulation of EZH2. Overall, these studies (Ma et al. 2017a, Prokopuk et al. 2018) show that EZH2 is a downstream target of androgen actions and androgens, through both extra-nuclear and nuclear signaling can regulate epigenetic modulators such as EZH2 in female reproductive tissues.

Another histone-modifying enzyme that is known (Metzger et al. 2005) to be involved in androgen-induced gene expression is lysine-specific histone demethylase $1 \mathrm{~A}$ (LSD1, also referred to as KDM1A), a histone demethylase. LDS1 is an important component of the androgen receptor transcription complex. LSD1 interacts with androgen receptor and demethylates monomethylated and dimethylated $\mathrm{H} 3 \mathrm{~K} 4 / 9$ repressive marks which in turn stimulates AR gene transcription. While the role of LSD1 with respect to androgen actions in the ovary and/or female fertility has not yet been studied, LSD1 has been reported to be a potential mediator of ovarian cancer (Chen et al. 2015).

In humans, there have been very limited studies involving androgen-induced histone modifications. Nelson-DeGrave et al. (2004) showed an increase in androgen production in valproate (a drug used in patients with epilepsy) treated cultured human theca cells. Valproate-induced ovarian androgen biosynthesis is caused by histone acetylation of CYP11A and CYP17 
that increases the transcription of these steroidogenic genes (Table 1). Further studies are needed not only to understand postnatal androgen actions in the ovary or its role in women's health in general but also to identify/ study the other epigenetic histone modulators regulated by androgens and to elucidate the underlying mechanism of their regulation.

\section{DNA modifications}

In the DNA, there are a number of sites that contain cytosine nucleotides followed by guanine nucleotides arranged in a linear sequence along the 5'-3' direction called the CpG sites. The cytosines in the CpG dinucleotides can be methylated/demethylated by enzymes called methyltransferases/demethylases. Methylation of CpG sites (hyper-methylation) within a gene causes gene silencing while demethylation or a lack of methyl mark (hypo-methylation) on these sites influences gene activation (Costello \& Plass 2001) (Fig. 2).

\section{PCOS patients}

A large number of studies have used DNA methylome profiling to assess if epigenetic dysregulation of critical ovarian genes may contribute to ovarian defects in PCOS (Wang et al. 2014, Sagvekar et al. 2017, Desmawati et al. 2018). Given that hyper-androgenism is the primary feature of PCOS (Pasquali et al. 2016), it is now being

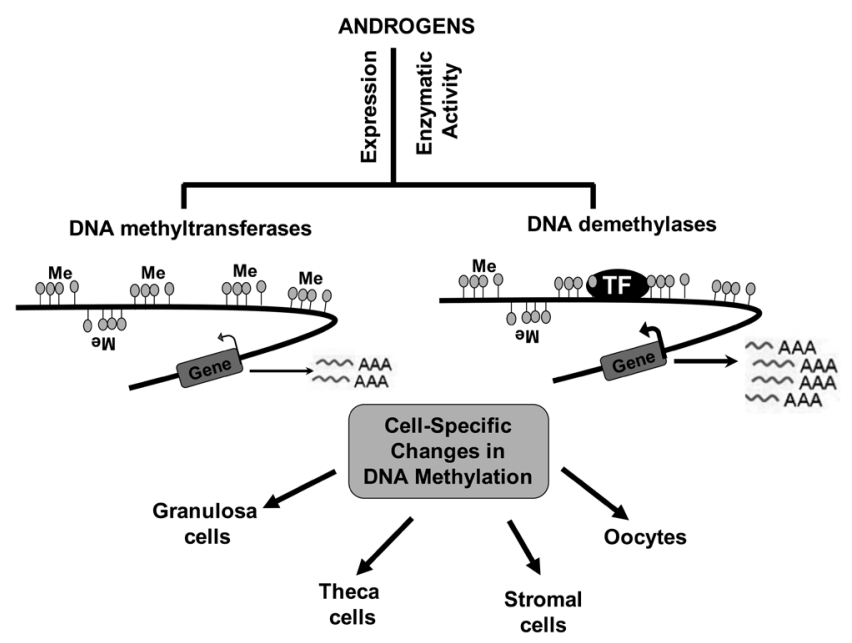

Figure 2

Androgen-induced regulation of DNA methylation: It is being proposed that androgens may indirectly regulate gene expression through regulating the expression and/or enzymatic activity of DNA methyltransferases and/or DNA demethylases that in turn mediates the methylation pattern of CpG islands. The changes in the methylation pattern are tissue-/cell-type-specific and causes developmental reprogramming.

(C) 2021 Society for Endocrinology Published by Bioscientifica Ltd. Printed in Great Britain hypothesized that elevated androgen levels may directly affect the methylation pattern of many of these genes. However, the underlying mechanism(s) by which androgens may regulate $\mathrm{CpG}$ methylation pattern of ovarian genes under PCOS condition remains to be elucidated. Interestingly, studies in prostate cancer and in the testis, show that androgens through AR can regulate the expression of TET (ten-eleven translocation) proteins that catalyzes the hydroxylation of DNA 5-methylcytosine, $5 \mathrm{mC}$ to 5-hydroxymethylcytosine, $5 \mathrm{hmC}$ (Takayama et al. 2015) as well as the expression and activity of DNMTs (DNA methyltransferase) (Anway \& Skinner 2008, Anway et al. 2008, Cowin et al. 2010, Chu et al. 2014). Notably, in silico analysis of the 5'-promoter regions of the human DNMT1 and DNMT3A gene shows the presence of androgen response elements (AREs), thereby suggesting that the expression of these DNA methyltransferases can be directly regulated by androgens (unpublished data from authors laboratory). Furthermore, in normal prostate cells androgens through AR-mediate activity dynamically regulate the DNA methylation patterns of many of its target genes (Dhiman et al. 2015). The understanding of androgen-induced regulation of DNA methylation pattern in PCOS condition is still in the early stages and whether androgens regulate the expression and/or activity of TET proteins and DNMTs in the ovary needs to be established. However, the first step toward directly linking androgen actions to dynamic changes in the DNA methylation pattern is to identify the genes or the CpG sites that are hypo- or hyper-methylated in hyper-androgenic PCOS patients, so that these genes/sites can be used as downstream endpoints. Here we provide a list of genes/CpG sites that have been reported to be hypo- or hyper-methylated in PCOS ovary (has elevated androgen levels) and discuss their ovarian (dys)function with respect to PCOS pathophysiology.

Hypo-methylation It has been proposed that aberrant DNA methylation patterns could serve as epigenetic biomarkers for the detection of PCOS. For example, it is well-established that the luteinizing hormone/ choriogonadotropin receptor (LHCGR) and its ligand, LH, play a critical role in folliculogenesis/ovulation (Filicori 1999). In PCOS, LHCGR is overexpressed in granulosa cells and is thought to be an underlying cause for the anovulation phenotype associated with PCOS (Kanamarlapudi et al. 2016). Intriguingly, in granulosa cells and peripheral blood cells of PCOS patients the LHCGR gene has been reported to be hypo-methylated (Wang et al. 2014) which provides 
a mechanistic understanding of how the expression of LHCGR is upregulated in a hyper-androgenic condition like PCOS. Moreover, studies (Sagvekar et al. 2019) in cumulus granulosa cells isolated from PCOS women show 2977 CpGs representing 2063 genes to be hypomethylated while 2509 CpGs within 1777 genes to be hyper-methylated. Interestingly, the promoter region of the androgen receptor has also been reported to be hypo-methylated in granulosa cells of women with PCOS as compared to controls, resulting in increased AR levels in PCOS women (Desmawati et al. 2018). Global methylation studies provide further insights about the role of epigenetic modulation in the pathogenesis of PCOS. Granulosa cells isolated from PCOS patients show a $25 \%$ reduction in the level of 5-methylcytosine (5-mC) in comparison to the control group (Pan et al. 2018). Moreover, the promoter regions of several genes related to lipid metabolism and steroid synthesis (CD9, NR4A1, EDN2, BNIP3, and LIF) have been reported to be hypomethylated in granulosa cells of PCOS patients (Pan et al. 2018) (Table 2).

Hyper-methylation Hyper-methylation of $\mathrm{CpG}$ islands on gene promoter led to transcriptional repression. A study (Qu et al. 2012) in primary granulosa cells isolated from PCOS patients has reported two hypermethylated $\mathrm{CpG}$ sites in the promoter of peroxisome proliferator-activated receptor 1 (PPARG1) gene and five hypo-methylated $\mathrm{CpG}$ sites in the promoter of nuclear corepressor (NCOR1) gene. Correlating with this, granulosa cells from these PCOS patients have lower mRNA expression of PPARG1 compared to nonPCOS patients (Qu et al. 2012) (Table 2). PPARG1 is a nonsteroidal nuclear hormone receptor that plays an important role in ovarian function (Froment et al. 2003) and PPAR agonists have been used as a therapeutic option in PCOS patients to improve ovulation rates (Ehrmann et al. 1997, Azziz et al. 2001). Furthermore, granulosa cells from hyper-androgenic PCOS patients show higher levels of NCOR1 and HDAC3 mRNA levels (Qu et al. 2012). Mechanistically, inhibition of the PI3K pathway by LY294002 in human primary granulosa cells alters androgen-induced inhibition of PPARG1 and increased expression of HDAC3 mRNA (Qu et al. 2012). This shows that extra-nuclear androgen signaling is also involved in regulating PPARG1 and HDAC3 expression. However, whether this androgen-induced extra-nuclear signaling (PI3K pathway) also mediates androgen-induced CpG methylation thereby modulating gene expression needs further elucidation. Moreover, NCOR1 and HDAC3 have been shown to epigenetically regulate circadian metabolic physiology (Alenghat et al. 2008) and recently, it has been proposed that disruption of the circadian system can impact female fertility and health (Sen \& Sellix 2016). Therefore, it can be speculated that androgen-induced modification of the CpG methylation pattern may lead to altered expression of PPARG1, NCOR1, and HDAC3 in granulosa cells of PCOS patients (Table 2), which may be one of the contributing factors to ovarian and metabolic dysfunction associated with PCOS.

In addition to directly affecting the $\mathrm{CpG}$ sites on gene promoters, androgens also indirectly regulate the expression of genes through epigenetic modulation. For example, miRNA have been shown to play a major role in PCOS pathogenesis (Mao et al. 2021). Combinatorial analyses of RNA-seq, miRNA-seq, and methylated DNA-binding domain sequencing in granulosa cells from PCOS patients have shown hyper-methylation of $m i R-429, m i R-141-3 p$, and $m i R-126-3 p$ promoters result in lower expression of these miRNAs that is correlated with upregulation of the genes targeted by these miRNAs, namely, XIAP (X-linked inhibitor of apoptosis protein), BRD3 (Bromodomain Containing 3), MAPK14 (Mitogenactivated protein kinase 14), and SLC7A5 (Solute Carrier Family 7) (Mao et al. 2021).

The above-cited studies show mostly correlative effects and the molecular mechanisms by which androgen may regulate DNA methylation pattern in the ovary are still poorly understood and therefore needs further investigation.

\section{Hyper-androgenic PCOS animal models \\ Prenatal androgen treatment Studies (Xia et al. 2015)} in prenatally androgenized rat (3mg testosterone from days 16 to 19 of gestation) models show five CpG sites in the Ar gene (CpG p87, p91, p93, p98, p150) and one CpG site in Cyp11a1 (CpG p953) that are significantly hypo-methylated (Table 2). Additionally, genome-wide CpG methylation analysis in the prenatally androgenized rat (T propionate $2.5 \mathrm{mg} / \mathrm{mL} /$ day from days 16 to 18 of gestation) ovaries revealed 2497 differentially methylated genes, 528 of which were hyper-methylated (Zhang et al. 2014). In this study, gene ontology analysis of these 528 hyper-methylated genes showed that these genes are mainly involved in reproductive development, embryonic development, and lipid and glucose metabolic processes (Table 2). This emphasizes that changes in the DNA methylation status of genes induced by prenatal androgenization may be an underlying mechanism for some of the phenotypes reported in the prenatally 
Table 2 Androgen-induced site-specific DNA methylation in the ovary.

\begin{tabular}{|c|c|c|c|c|c|}
\hline Species & Site of impact & Treatment & DNA methylation status & Related genes & References \\
\hline Human & $\begin{array}{l}\text { Peripheral blood } \\
\text { cells and } \\
\text { granulosa cells }\end{array}$ & Prenatal & Hypomethylation & LHCGR & Wang et al. 2014 \\
\hline Human & $\begin{array}{l}\text { Cumulus } \\
\text { granulosa cells }\end{array}$ & Prenatal & $\begin{array}{l}\text { Hypomethylation (2977 CpGs) } \\
\text { and hypermethylation ( } 2509 \\
\text { CpGs) }\end{array}$ & $\begin{array}{l}2063 \text { genes } \\
1777 \text { genes }\end{array}$ & $\begin{array}{l}\text { Sagvekar } \\
\text { et al. } 2019\end{array}$ \\
\hline Human & Granulosa cells & Prenatal & Hypomethylation & $A R$ & $\begin{array}{r}\text { Desmawati } \\
\text { et al. } 2018\end{array}$ \\
\hline Human & Granulosa cells & Prenatal & Global methylation & $\begin{array}{l}\text { GSTA1, CD74, ANGPTL4, CD9, NR4A1, } \\
\text { EDN2, PTX3, LIF, SLC12A8, PEX3, } \\
\text { CYP17A1, SERPINE1, DIRAS3, BNIP3, } \\
\text { and SPP1 }\end{array}$ & Pan et al. 2018 \\
\hline Human & Granulosa cells & Prenatal & CpG methylation & PPARG1, NCOR1 and HDAC3 & Qu et al. 2012 \\
\hline Human & Granulosa cells & Prenatal & $\begin{array}{l}\text { Hypermethylation (miR-429, } \\
\text { miR-141-3p, and miR-126-3p') }\end{array}$ & $X I A P, B R D 3, M A P K 14$ and SLC7A5 & Mao et al. 2021 \\
\hline Sheep & Stromal cells & Prenatal & Hypermethylation & DNMT3A and DNMT3B & Guo et al. 2019 \\
\hline Sheep & Granulosa cells & Prenatal & Hypermethylation & DNMT1 & Guo et al. 2019 \\
\hline Zebrafish & Ovaries & Prenatal & Global DNA methylation & $\begin{array}{l}\text { Genes related to glucose } \\
\text { metabolism }\end{array}$ & Xu et al. 2014 \\
\hline Wistar rats & Theca cells & Prenatal & Hypomethylation & GATA6 and StAR & $\begin{array}{l}\text { Salehi Jahromi } \\
\text { et al. } 2018\end{array}$ \\
\hline Rat & Ovaries & Prenatal & Hypomethylation & $A R$ and Cyp11a1 & Xia et al. 2015 \\
\hline Rat & Ovaries & Prenatal & Differential methylation & $\begin{array}{l}\text { Genes involved in reproductive and } \\
\text { embryonic development, lipid and } \\
\text { glucose metabolic processes }\end{array}$ & Zhang et al. 2014 \\
\hline Mouse & Ovaries & Postnatal & Hypomethylation & Lhr & Zhu et al. 2010 \\
\hline Mouse & Oocytes & Postnatal & Hypomethylation & Dnmt1 & Eini et al. 2017 \\
\hline
\end{tabular}

androgenized animals. For example, genes involved in ovarian follicle, female genitalia, and germ cell development, as well as mammary gland development and mammary gland duct morphogenesis were significantly hyper-methylated (Zhang et al. 2014). Repression of gene expression by hyper-methylation in prenatally androgenized murine models leads to an increase in anogenital distance, agenesis of the lower vagina, absence of nipples, and reduced papillary numbers (McCoy \& Shirley 1992, Rhees et al. 1997, Wolf et al. 2002). Offspring from prenatally androgenized (5 $\mathrm{mg}$ free testosterone in $500 \mathrm{~mL}$ solvent on day 20 of gestation) Wistar rats also show (Salehi Jahromi et al. 2018) hypo-methylation at -520 and -822 positions in the Gata 6 and the StAR promoter respectively (Table 2). Interestingly, in PCOS patients, expression of both Gata 6 (Ho et al. 2005) and StAR (Jakimiuk et al. 2001) genes are increased in theca cells. Similarly, the Lhr gene is hypo-methylated in the ovaries of the DHEA-induced mouse PCOS model (Zhu et al. 2010) that correlates with higher LHR levels in PCOS patients, as mentioned above.

Changes in DNA methylation are caused by DNA methyltransferases (DNMTs) and studies (Gravina et al. 2011, Zhu et al. 2011, Chu et al. 2014) in cancer cells have shown that androgen can increase the expression and activity of DNMTs. Therefore, it is highly possible that in the ovary too, androgen-induced modulation of DNA methylation can be mediated through regulation of expression/activity of DNMTs (Fig. 2). For example, a recent study (Guo et al. 2019) comparing granulosa, theca, and stroma cells isolated from ovaries of prenatally androgenized (100 $\mathrm{mg} \mathrm{T}$ propionate from days 30 to 90 of gestation) adult sheep reported a significant increase in the expression of DNMT1 and a decrease in DNMT3B in the granulosa cells. Additionally, stromal cells from the same ovaries had higher expression of DNMT3A and DNMT3B genes (Table 2). DNMT1 is the primary methyltransferase that catalyzes the addition of methyl groups to specific CpG structures in the DNA while DNMT3A and DNMT3B serve as de novo methyltransferases (Hervouet et al. 2018). Therefore, similar to histone modifications, these studies also show that in the ovary, androgens can have differential effects on DNA methylation in a cell-specific manner.

Post-natal androgen treatment There are limited studies on the effect of post-natal androgen treatment on the epigenetic modification of the DNA in the ovary. In zebrafish, exposure to testosterone, and its metabolite dihydrotestosterone (DHT), during development, show that early-life exposure can induce changes in global DNA 
methylation status in the ovary (Xu et al. 2014) (Table 2). Furthermore, testosterone has a stronger effect on global DNA methylation in the ovary compared to DHT, thus, suggesting that the aromatization of testosterone to estrogen might play a role in the epigenetic programming effect. This study (Xu et al. 2014) also reported that these epigenetic effects can be trans-generationally transmitted from the exposed F1 to the unexposed F2 generation. In mammals, prepubertal female mice treated with DHEA (6 mg per 100 g body weight) show a decline in DNA methylation and reduced expression of Dnmt1 in oocytes (Eini et al. 2017) (Table 2). Further studies are needed to understand how androgens regulate the expression/ activity of the DNMTs.

\section{Concluding remarks and future perspectives}

Collectively, while there is now some evidence of androgeninduced epigenetic modifications, we are just beginning to understand the effect of androgen-induced epigenetic modulation in female reproduction and health. Recent studies have mainly been focused on pinpointing the changes induced by androgens in the DNA methylation status of genes, post-translational modifications of histones, and how these epigenetic modifications change gene expression. These studies now provide some mechanistic understanding of androgen actions in the ovary, both under normal and pathophysiological conditions like PCOS. However, there are very few studies and they provide a limited understanding of androgen-induced epigenetic modulation in the ovary. Moreover, how androgens regulate specific epigenetic enzymes to modulate the epigenome is poorly understood. Notably, posttranslational modifications of histone-modifying enzymes, in particular phosphorylation, contribute to developmental programming (Trevino et al. 2015). For example, signaling pathways known to be activated by extra-nuclear androgen signaling such as PI3K/Akt, MAPK, and PKA pathways, have been shown to modify and regulate the activity of various epigenetic enzymes (Trevino et al. 2015, Ma et al. 2017a). Therefore, elucidating how androgen-induced nuclear and/or extra-nuclear signals regulate epigenetic changes will provide novel mechanistic insights about androgen actions in both normal and pathophysiological conditions as well as in androgen-induced developmental programming. Given the physiological importance of androgens in women's reproductive health, this knowledge is imperative to develop novel strategies to improve female fertility and women's health.

\section{Declaration of interest}

The authors declare that there is no conflict of interest that could be perceived as prejudicing the impartiality of this review.

\section{Funding}

This review was made possible by the NIH (NICHD) R01HD086062 grant, USDA-HATCH project MICL02383 and MSU AgBioResearch awarded to A S. I.S was partially supported by $\mathrm{NIH}$ (NICHD) under Award Number T32HD087166, MSU AgBio Research, and Michigan State University. The content is solely the responsibility of the authors and does not necessarily represent the official views of the National Institutes of Health.

\section{References}

Abbott DH, Dumesic DA \& Franks S 2002 Developmental origin of polycystic ovary syndrome - a hypothesis. Journal of Endocrinology 174 1-5. (https://doi.org/10.1677/joe.0.1740001)

Abbott DH, Barnett DK, Bruns CM \& Dumesic DA 2005 Androgen excess fetal programming of female reproduction: a developmental aetiology for polycystic ovary syndrome? Human Reproduction Update $\mathbf{1 1}$ 357-374. (https://doi.org/10.1093/humupd/dmi013)

Abbott DH, Padmanabhan V \& Dumesic DA 2006 Contributions of androgen and estrogen to fetal programming of ovarian dysfunction. Reproductive Biology and Endocrinology 4 17. (https://doi. org/10.1186/1477-7827-4-17)

Abbott DH, Barnett DK, Levine JE, Padmanabhan V, Dumesic DA, Jacoris S \& Tarantal AF $2008 a$ Endocrine antecedents of polycystic ovary syndrome in fetal and infant prenatally androgenized female rhesus monkeys. Biology of Reproduction 79 154-163. (https://doi. org/10.1095/biolreprod.108.067702)

Abbott DH, Zhou R, Bird IM, Dumesic DA \& Conley AJ 2008b Fetal programming of adrenal androgen excess: lessons from a nonhuman primate model of polycystic ovary syndrome. Endocrine Development 13 145-158. (https://doi.org/10.1159/000134831)

Alenghat T, Meyers K, Mullican SE, Leitner K, Adeniji-Adele A, Avila J, Bucan M, Ahima RS, Kaestner KH \& Lazar MA 2008 Nuclear receptor corepressor and histone deacetylase 3 govern circadian metabolic physiology. Nature 456 997-1000. (https://doi.org/10.1038/nature07541)

Anway MD \& Skinner MK 2008 Transgenerational effects of the endocrine disruptor vinclozolin on the prostate transcriptome and adult onset disease. Prostate 68 517-529. (https://doi.org/10.1002/pros.20724)

Anway MD, Rekow SS \& Skinner MK 2008 Transgenerational epigenetic programming of the embryonic testis transcriptome. Genomics 91 30-40. (https://doi.org/10.1016/j.ygeno.2007.10.002)

Azziz R, Ehrmann D, Legro RS, Whitcomb RW, Hanley R, Fereshetian AG, O'keefe M, Ghazzi MN \& PCOS/Troglitazone Study Group 2001 Troglitazone improves ovulation and hirsutism in the polycystic ovary syndrome: a multicenter, double blind, placebo-controlled trial. Journal of Clinical Endocrinology and Metabolism 86 1626-1632. (https://doi.org/10.1210/jcem.86.4.7375)

Badeaux AI \& Shi Y 2013 Emerging roles for chromatin as a signal integration and storage platform. Nature Reviews: Molecular Cell Biology 14 211-224. (https://doi.org/10.1038/nrm3545)

Barad DH \& Gleicher N 2005 Increased oocyte production after treatment with dehydroepiandrosterone. Fertility and Sterility 84 756. (https:// doi.org/10.1016/j.fertnstert.2005.02.049)

Barad D \& Gleicher N 2006 Effect of dehydroepiandrosterone on oocyte and embryo yields, embryo grade and cell number in IVF. Human Reproduction 21 2845-2849. (https://doi.org/10.1093/humrep/del254)

Barker DJ 2007 The origins of the developmental origins theory. Journal of Internal Medicine 261 412-417. (https://doi.org/10.1111/j.13652796.2007.01809.x)

Blum R 2015 Stepping inside the realm of epigenetic modifiers. Biomolecular Concepts 6 119-136. (https://doi.org/10.1515/bmc-2015-0008) 
Bredfeldt TG, Greathouse KL, Safe SH, Hung MC, Bedford MT \& Walker CL 2010 Xenoestrogen-induced regulation of $\mathrm{EZH} 2$ and histone methylation via estrogen receptor signaling to PI3K/AKT. Molecular Endocrinology 24 993-1006. (https://doi.org/10.1210/me.2009-0438)

Bulger M \& Groudine M 2011 Functional and mechanistic diversity of distal transcription enhancers. Cell 144 327-339. (https://doi. org/10.1016/j.cell.2011.01.024)

Burger HG 2002 Androgen production in women. Fertility and Sterility 77 (Supplement 4) S3-S5. (https://doi.org/10.1016/s0015-0282(02)02985-0)

Cadagan D, Khan R \& Amer S 2014 Female adipocyte androgen synthesis and the effects of insulin. Molecular Genetics and Metabolism Reports 1 254-263. (https://doi.org/10.1016/j. ymgmr.2014.05.002)

Cha TL, Zhou BP, Xia W, Wu Y, Yang CC, Chen CT, Ping B, Otte AP \& Hung MC 2005 Akt-mediated phosphorylation of EZH2 suppresses methylation of lysine 27 in histone H3. Science 310 306-310. (https:// doi.org/10.1126/science.1118947)

Chen C, Ge J, Lu Q, Ping G, Yang C \& Fang X 2015 Expression of lysinespecific demethylase 1 in human epithelial ovarian cancer. Journal of Ovarian Research 8 28. (https://doi.org/10.1186/s13048-015-0155-1)

Chu M, Chang Y, Li P, Guo Y, Zhang K \& Gao W 2014 Androgen receptor is negatively correlated with the methylation-mediated transcriptional repression of miR-375 in human prostate cancer cells. Oncology Reports 31 34-40. (https://doi.org/10.3892/or.2013.2810)

Costello JF \& Plass C 2001 Methylation matters. Journal of Medical Genetics 38 285-303. (https://doi.org/10.1136/jmg.38.5.285)

Cowin PA, Gold E, Aleksova J, O’Bryan MK, Foster PM, Scott HS \& Risbridger GP 2010 Vinclozolin exposure in utero induces postpubertal prostatitis and reduces sperm production via a reversible hormone-regulated mechanism. Endocrinology 151 783-792. (https:// doi.org/10.1210/en.2009-0982)

DeFranco DB 2002 Navigating steroid hormone receptors through the nuclear compartment. Molecular Endocrinology 16 1449-1455. (https:// doi.org/10.1210/mend.16.7.0880)

Dhiman VK, Attwood K, Campbell MJ \& Smiraglia DJ 2015 Hormone stimulation of androgen receptor mediates dynamic changes in DNA methylation patterns at regulatory elements. Oncotarget 6 42575-42589. (https://doi.org/10.18632/oncotarget.6471)

Eder IE, Culig Z, Putz T, Nessler-Menardi C, Bartsch G \& Klocker H 2001 Molecular biology of the androgen receptor: from molecular understanding to the clinic. European Urology 40 241-251. (https:// doi.org/10.1159/000049782)

Edwards DP 2005 Regulation of signal transduction pathways by estrogen and progesterone. Annual Review of Physiology 67 335-376. (https:// doi.org/10.1146/annurev.physiol.67.040403.120151)

Ehrmann DA, Schneider DJ, Sobel BE, Cavaghan MK, Imperial J, Rosenfield RL \& Polonsky KS 1997 Troglitazone improves defects in insulin action, insulin secretion, ovarian steroidogenesis, and fibrinolysis in women with polycystic ovary syndrome. Journal of Clinical Endocrinology and Metabolism 82 2108-2116. (https://doi. org/10.1210/jcem.82.7.4069)

Eini F, Novin MG, Joharchi K, Hosseini A, Nazarian H, Piryaei A \& Bidadkosh A 2017 Intracytoplasmic oxidative stress reverses epigenetic modifications in polycystic ovary syndrome. Reproduction, Fertility, and Development 29 2313-2323. (https://doi.org/10.1071/RD16428)

Escobar-Morreale HF, Alvarez-Blasco F, Botella-Carretero JI \& LuqueRamirez M 2014 The striking similarities in the metabolic associations of female androgen excess and male androgen deficiency. Human Reproduction 29 2083-2091. (https://doi.org/10.1093/humrep/deu198)

Desmawati R, Febri R, Hestiantoro A \& Asmarinah A 2018 DNA methylation of the androgen receptor gene promoter in the granulosa cells of polycystic ovary syndrome patients. Journal of Physics: Conference Series 1073032078

Filicori M 1999 The role of luteinizing hormone in folliculogenesis and ovulation induction. Fertility and Sterility 71 405-414. (https://doi. org/10.1016/s0015-0282(98)00482-8)
Foecking EM, Mcdevitt MA, Acosta-Martinez M, Horton TH \& Levine JE 2008 Neuroendocrine consequences of androgen excess in female rodents. Hormones and Behavior 53 673-692. (https://doi. org/10.1016/j.yhbeh.2007.12.013)

Foradori CD, Weiser MJ \& Handa RJ 2008 Non-genomic actions of androgens. Frontiers in Neuroendocrinology 29 169-181. (https://doi. org/10.1016/j.yfrne.2007.10.005)

Franks S \& Hardy K 2018 Androgen action in the ovary. Frontiers in Endocrinology 9 452. (https://doi.org/10.3389/fendo.2018.00452)

Froment P, Fabre S, Dupont J, Pisselet C, Chesneau D, Staels B \& Monget P 2003 Expression and functional role of peroxisome proliferator-activated receptor-gamma in ovarian folliculogenesis in the sheep. Biology of Reproduction 69 1665-1674. (https://doi. org/10.1095/biolreprod.103.017244)

Gleicher N, Kim A, Weghofer A, Kushnir VA, Shohat-Tal A, Lazzaroni E, Lee HJ \& Barad DH 2013a Hypoandrogenism in association with diminished functional ovarian reserve. Human Reproduction $\mathbf{2 8}$ 1084-1091. (https://doi.org/10.1093/humrep/det033)

Gleicher N, Kim A, Weghofer A, Shohat-Tal A, Lazzaroni E, Lee HJ \& Barad DH 2013b Starting and resulting testosterone levels after androgen supplementation determine at all ages in vitro fertilization (IVF) pregnancy rates in women with diminished ovarian reserve (DOR). Journal of Assisted Reproduction and Genetics 30 49-62. (https:// doi.org/10.1007/s10815-012-9890-z)

Gore AC 2008 Developmental programming and endocrine disruptor effects on reproductive neuroendocrine systems. Frontiers in Neuroendocrinology 29 358-374. (https://doi.org/10.1016/j.yfrne.2008.02.002)

Gravina GL, Marampon F, Piccolella M, Motta M, Ventura L, Pomante R, Popov VM, Zani BM, Pestell RG, Tombolini V, et al. 2011 Hormonal therapy promotes hormone-resistant phenotype by increasing DNMT activity and expression in prostate cancer models. Endocrinology 152 4550-4561. (https://doi.org/10.1210/en.2011-1056)

Guo X, Puttabyatappa M, Thompson RC \& Padmanabhan V 2019 Developmental programming: contribution of epigenetic enzymes to antral follicular defects in the sheep model of PCOS. Endocrinology 160 2471-2484. (https://doi.org/10.1210/en.2019-00389)

Hammes SR \& Levin ER 2011 Minireview: recent advances in extranuclear steroid receptor actions. Endocrinology 152 4489-4495. (https://doi. org/10.1210/en.2011-1470)

Heemers HV \& Tindall DJ 2007 Androgen receptor (AR) coregulators: a diversity of functions converging on and regulating the AR transcriptional complex. Endocrine Reviews 28 778-808. (https://doi. org/10.1210/er.2007-0019)

Heinlein CA \& Chang C 2002 The roles of androgen receptors and androgen-binding proteins in nongenomic androgen actions. Molecular Endocrinology 16 2181-2187. (https://doi.org/10.1210/ me.2002-0070)

Hervouet E, Peixoto P, Delage-Mourroux R, Boyer-Guittaut M \& Cartron PF 2018 Specific or not specific recruitment of DNMTs for DNA methylation, an epigenetic dilemma. Clinical Epigenetics 1017. (https://doi.org/10.1186/s13148-018-0450-y)

Ho CKM, Wood JR, Stewart DR, Ewens K, Ankener W, Wickenheisser J, Nelson-Degrave V, Zhang Z, Legro RS, Dunaif A, et al. 2005 Increased transcription and increased messenger ribonucleic acid (mRNA) stability contribute to increased GATA6 mRNA abundance in polycystic ovary syndrome theca cells. Journal of Clinical Endocrinology and Metabolism 90 6596-6602. (https://doi.org/10.1210/jc.2005-0890)

Hu YC, Wang PH, Yeh S, Wang RS, Xie C, Xu Q, Zhou X, Chao HT, Tsai MY \& Chang C 2004 Subfertility and defective folliculogenesis in female mice lacking androgen receptor. PNAS 101 11209-11214. (https://doi.org/10.1073/pnas.0404372101)

Hyun K, Jeon J, Park K \& Kim J 2017 Writing, erasing and reading histone lysine methylations. Experimental and Molecular Medicine 49 e324. (https://doi.org/10.1038/emm.2017.11)

Jakimiuk AJ, Weitsman SR, Navab A \& Magoffin DA 2001 Luteinizing hormone receptor, steroidogenesis acute regulatory protein, and 
steroidogenic enzyme messenger ribonucleic acids are overexpressed in thecal and granulosa cells from polycystic ovaries. Journal of Clinical Endocrinology and Metabolism 86 1318-1323. (https://doi. org/10.1210/jcem.86.3.7318)

Jo M \& Curry Jr TE 2006 Luteinizing hormone-induced RUNX1 regulates the expression of genes in granulosa cells of rat periovulatory follicles. Molecular Endocrinology 20 2156-2172. (https://doi.org/10.1210/ me.2005-0512)

Kanamarlapudi V, Gordon UD \& Lopez Bernal A 2016 Luteinizing hormone/chorionic gonadotrophin receptor overexpressed in granulosa cells from polycystic ovary syndrome ovaries is functionally active. Reproductive Biomedicine Online 32 635-641. (https://doi. org/10.1016/j.rbmo.2016.03.003)

Kang HY, Cho CL, Huang KL, Wang JC, Hu YC, Lin HK, Chang C \& Huang KE 2004 Nongenomic androgen activation of phosphatidylinositol 3-kinase/Akt signaling pathway in MC3T3-E1 osteoblasts. Journal of Bone and Mineral Research 19 1181-1190. (https://doi.org/10.1359/JBMR.040306)

Kim S \& Kaang BK 2017 Epigenetic regulation and chromatin remodeling in learning and memory. Experimental and Molecular Medicine 49 e281. (https://doi.org/10.1038/emm.2016.140)

Klinge CM 2018 Steroid hormone receptors and signal transduction processes. In Principles of Endocrinology and Hormone Action. Eds A Belfiore \& D Leroith. Cham: Springer International Publishing.

Levin ER 2015 Extranuclear steroid receptors are essential for steroid hormone actions. Annual Review of Medicine 66 271-280. (https://doi. org/10.1146/annurev-med-050913-021703)

Levin ER \& Hammes SR 2016 Nuclear receptors outside the nucleus: extranuclear signalling by steroid receptors. Nature Reviews: Molecular Cell Biology 17 783-797. (https://doi.org/10.1038/nrm.2016.122)

London DR 1987 The consequences of hyperandrogenism in young women. Journal of the Royal Society of Medicine 80 741-745. (https:// doi.org/10.1177/014107688708001206)

Ma X, Hayes E, Biswas A, Seger C, Prizant H, Hammes SR \& Sen A 2017a Androgens regulate ovarian gene expression through modulation of Ezh2 expression and activity. Endocrinology 158 2944-2954. (https:// doi.org/10.1210/en.2017-00145)

Ma Y, Andrisse S, Chen Y, Childress S, Xue P, Wang Z, Jones D, Ko C, Divall S \& Wu S 2017b Androgen receptor in the ovary theca cells plays a critical role in androgen-induced reproductive dysfunction. Endocrinology 158 98-108. (https://doi.org/10.1210/en.2016-1608)

Mao Z, Li T, Zhao H, Qin Y, Wang X \& Kang Y 2021 Identification of epigenetic interactions between microRNA and DNA methylation associated with polycystic ovarian syndrome. Journal of Human Genetics 66 123-137. (https://doi.org/10.1038/s10038-020-0819-6)

Matsumoto T, Sakari M, Okada M, Yokoyama A, Takahashi S, Kouzmenko A \& Kato S 2013 The androgen receptor in health and disease. Annual Review of Physiology 75 201-224. (https://doi. org/10.1146/annurev-physiol-030212-183656)

McCoy SJ \& Shirley BA 1992 Effects of prenatal administration of testosterone and cortisone on the reproductive system of the female rat. Life Sciences 50 621-628. (https://doi.org/10.1016/00243205(92)90248-n)

Metzger E, Wissmann M, Yin N, Muller JM, Schneider R, Peters AH, Gunther T, Buettner R \& Schule R 2005 LSD1 demethylates repressive histone marks to promote androgen-receptor-dependent transcription. Nature 437 436-439. (https://doi.org/10.1038/nature04020)

Nelson-DeGrave VL, Wickenheisser JK, Cockrell JE, Wood JR, Legro RS, Strauss JF, 3RD \& Mcallister JM 2004 Valproate potentiates androgen biosynthesis in human ovarian theca cells. Endocrinology 145 799-808. (https://doi.org/10.1210/en.2003-0940)

Nugent BM, Tobet SA, Lara HE, Lucion AB, Wilson ME, Recabarren SE \& Paredes AH 2012 Hormonal programming across the lifespan. Hormone and Metabolic Research 44 577-586. (https://doi. org/10.1055/s-0032-1312593)
Padmanabhan V \& Veiga-Lopez A 2013 Animal models of the polycystic ovary syndrome phenotype. Steroids 78 734-740. (https://doi. org/10.1016/j.steroids.2013.05.004)

Padmanabhan V, Veiga-Lopez A, Herkimer C, Abi Salloum B, Moeller J, Beckett E \& Sreedharan R 2015 Developmental programming: prenatal and postnatal androgen antagonist and insulin sensitizer interventions prevent advancement of puberty and improve LH surge dynamics in prenatal testosterone-treated sheep. Endocrinology 156 2678-2692. (https://doi.org/10.1210/en.2015-1235)

Padmanabhan V, Cardoso RC \& Puttabyatappa M 2016 Developmental programming, a pathway to disease. Endocrinology 157 1328-1340. (https://doi.org/10.1210/en.2016-1003)

Pan JX, Tan YJ, Wang FF, Hou NN, Xiang YQ, Zhang JY, Liu Y, Qu F, Meng Q, Xu J, et al. 2018 Aberrant expression and DNA methylation of lipid metabolism genes in PCOS: a new insight into its pathogenesis. Clinical Epigenetics 10 6. (https://doi.org/10.1186/s13148-018-0442-y)

Pasquali R, Zanotti L, Fanelli F, Mezzullo M, Fazzini A, Morselli Labate AM, Repaci A, Ribichini D \& Gambineri A 2016 Defining hyperandrogenism in women with polycystic ovary syndrome: a challenging perspective. Journal of Clinical Endocrinology and Metabolism 101 2013-2022. (https://doi.org/10.1210/jc.2015-4009)

Poston L 2010 Developmental programming and diabetes - the human experience and insight from animal models. Best Practice and Research: Clinical Endocrinology and Metabolism 24 541-552. (https://doi. org/10.1016/j.beem.2010.05.007)

Prizant H, Gleicher N \& Sen A 2014 Androgen actions in the ovary: balance is key. Journal of Endocrinology 222 R141-R151. (https://doi. org/10.1530/JOE-14-0296)

Prokopuk L, Hogg K \& Western PS 2018 Pharmacological inhibition of EZH2 disrupts the female germline epigenome. Clinical Epigenetics 10 33. (https://doi.org/10.1186/s13148-018-0465-4)

Puttabyatappa M \& Padmanabhan V 2018 Developmental programming of ovarian functions and dysfunctions. Vitamins and Hormones $\mathbf{1 0 7}$ 377-422. (https://doi.org/10.1016/bs.vh.2018.01.017)

Qu F, Wang FF, Yin R, Ding GL, El-Prince M, Gao Q, Shi BW, Pan HH, Huang YT, Jin M, et al. 2012 A molecular mechanism underlying ovarian dysfunction of polycystic ovary syndrome: hyperandrogenism induces epigenetic alterations in the granulosa cells. Journal of Molecular Medicine 90 911-923. (https://doi. org/10.1007/s00109-012-0881-4)

Rhees RW, Kirk BA, Sephton S \& Lephart ED 1997 Effects of prenatal testosterone on sexual behavior, reproductive morphology and LH secretion in the female rat. Developmental Neuroscience 19 430-437. (https://doi.org/10.1159/000111240)

Rojanasakul Y 2013 Linking JNK-STAT3-Akt signaling axis to EZH2 phosphorylation: a novel pathway of carcinogenesis. Cell Cycle $\mathbf{1 2}$ 202-203. (https://doi.org/10.4161/cc.23419)

Sagvekar P, Mangoli V, Desai S, Patil A \& Mukherjee S 2017 LINE1 CpG-DNA hypomethylation in granulosa cells and blood leukocytes is associated with PCOS and related traits. Journal of Clinical Endocrinology and Metabolism 102 1396-1405. (https://doi. org/10.1210/jc.2016-2645)

Sagvekar P, Kumar P, Mangoli V, Desai S \& Mukherjee S 2019 DNA methylome profiling of granulosa cells reveals altered methylation in genes regulating vital ovarian functions in polycystic ovary syndrome. Clinical Epigenetics 11 61. (https://doi.org/10.1186/s13148019-0657-6)

Salehi Jahromi M, Hill JW, Ramezani Tehrani F \& Zadeh-Vakili A 2018 Hypomethylation of specific CpG sites in the promoter region of steroidogeneic genes (GATA6 and StAR) in prenatally androgenized rats. Life Sciences 207 105-109. (https://doi.org/10.1016/j. lfs.2018.05.052)

Sen A \& Hammes SR 2010 Granulosa cell-specific androgen receptors are critical regulators of ovarian development and function. Molecular Endocrinology 24 1393-1403. (https://doi.org/10.1210/me.2010-0006) https://joe.bioscientifica.com

https://doi.org/10.1530/JOE-20-0578 (c) 2021 Society for Endocrinology Published by Bioscientifica Ltd. Printed in Great Britain 
Sen A \& Sellix MT 2016 The circadian timing system and environmental circadian disruption: from follicles to fertility. Endocrinology $\mathbf{1 5 7}$ 3366-3373. (https://doi.org/10.1210/en.2016-1450)

Sen A, Prizant H, Light A, Biswas A, Hayes E, Lee HJ, Barad D, Gleicher N \& Hammes SR 2014 Androgens regulate ovarian follicular development by increasing follicle stimulating hormone receptor and microRNA-125b expression. PNAS 111 3008-3013. (https://doi. org/10.1073/pnas.1318978111)

Shiina H, Matsumoto T, Sato T, Igarashi K, Miyamoto J, Takemasa S, Sakari M, Takada I, Nakamura T, Metzger D, et al. 2006 Premature ovarian failure in androgen receptor-deficient mice. PNAS 103 224-229. (https://doi.org/10.1073/pnas.0506736102)

Sinha N, Roy S, Huang B, Wang J, Padmanabhan V \& Sen A 2020 Developmental programming: prenatal testosterone-induced epigenetic modulation and its effect on gene expression in sheep ovary. Biology of Reproduction 102 1045-1054. (https://doi.org/10.1093/biolre/ioaa007)

Solano ME \& Arck PC 2019 Steroids, pregnancy and fetal development. Frontiers in Immunology 10 3017. (https://doi.org/10.3389/ fimmu.2019.03017)

Stelloo S, Bergman AM \& Zwart W 2019 Androgen receptor enhancer usage and the chromatin regulatory landscape in human prostate cancers. Endocrine Related Cancers 26 R267-R285. (https://doi. org/10.1530/ERC-19-0032)

Takayama K, Misawa A, Suzuki T, Takagi K, Hayashizaki Y, Fujimura T, Homma Y, Takahashi S, Urano T \& Inoue S 2015 TET2 repression by androgen hormone regulates global hydroxymethylation status and prostate cancer progression. Nature Communications 6 8219. (https:// doi.org/10.1038/ncomms9219)

Thakur MK \& Paramanik V 2009 Role of steroid hormone coregulators in health and disease. Hormone Research 71 194-200. (https://doi. org/10.1159/000201107)

Trevino LS, Wang Q \& Walker CL 2015 Phosphorylation of epigenetic 'readers, writers and erasers': implications for developmental reprogramming and the epigenetic basis for health and disease. Progress in Biophysics and Molecular Biology 118 8-13. (https://doi. org/10.1016/j.pbiomolbio.2015.02.013)

Walters KA 2015 Role of androgens in normal and pathological ovarian function. Reproduction 149 R193-R218. (https://doi.org/10.1530/REP14-0517)

Walters KA \& Handelsman DJ 2018 Role of androgens in the ovary. Molecular and Cellular Endocrinology 465 36-47. (https://doi. org/10.1016/j.mce.2017.06.026)

Walters KA, Allan CM, Jimenez M, Lim PR, Davey RA, Zajac JD, Illingworth P \& Handelsman DJ 2007 Female mice haploinsufficient for an inactivated androgen receptor (AR) exhibit age-dependent defects that resemble the AR null phenotype of dysfunctional late follicle development, ovulation, and fertility. Endocrinology 148 3674-3684. (https://doi.org/10.1210/en.2007-0248)

Walters KA, Middleton LJ, Joseph SR, Hazra R, Jimenez M, Simanainen U, Allan CM \& Handelsman DJ 2012 Targeted loss of androgen receptor signaling in murine granulosa cells of preantral and antral follicles causes female subfertility. Biology of Reproduction 87 151. (https://doi. org/10.1095/biolreprod.112.102012)

Walters KA, Simanainen U \& Gibson DA 2016 Androgen action in female reproductive physiology. Current Opinion in Endocrinology, Diabetes, and Obesity 23 291-296. (https://doi.org/10.1097/MED.0000000000000246)

Walters KA, Edwards MC, Tesic D, Caldwell ASL, Jimenez M, Smith JT \& Handelsman DJ 2018 The role of central androgen receptor actions in regulating the hypothalamic-pituitary-ovarian axis. Neuroendocrinology 106 389-400. (https://doi.org/10.1159/000487762)

Walters KA, Rodriguez Paris V, Aflatounian A \& Handelsman DJ 2019 Androgens and ovarian function: translation from basic discovery research to clinical impact. Journal of Endocrinology 242 R23-R50. (https://doi.org/10.1530/JOE-19-0096)

Wang P, Zhao H, Li T, Zhang W, Wu K, Li M, Bian Y, Liu H, Ning Y, Li G, et al. 2014 Hypomethylation of the LH/choriogonadotropin receptor promoter region is a potential mechanism underlying susceptibility to polycystic ovary syndrome. Endocrinology $\mathbf{1 5 5}$ 1445-1452. (https://doi.org/10.1210/en.2013-1764)

Wei Y, Chen YH, Li LY, Lang J, Yeh SP, Shi B, Yang CC, Yang JY, Lin CY, Lai CC, et al. 2011 CDK1-dependent phosphorylation of EZH2 suppresses methylation of H3K27 and promotes osteogenic differentiation of human mesenchymal stem cells. Nature Cell Biology 13 87-94. (https://doi.org/10.1038/ncb2139)

Wilkenfeld SR, Lin C \& Frigo DE 2018 Communication between genomic and non-genomic signaling events coordinate steroid hormone actions. Steroids 133 2-7. (https://doi.org/10.1016/j. steroids.2017.11.005)

Wolf CJ, Hotchkiss A, Ostby JS, Leblanc GA \& Gray Jr LE 2002 Effects of prenatal testosterone propionate on the sexual development of male and female rats: a dose-response study. Toxicological Sciences 65 71-86. (https://doi.org/10.1093/toxsci/65.1.71)

Wu S, Chen Y, Fajobi T, Divall SA, Chang C, Yeh S \& Wolfe A 2014 Conditional knockout of the androgen receptor in gonadotropes reveals crucial roles for androgen in gonadotropin synthesis and surge in female mice. Molecular Endocrinology 28 1670-1681. (https://doi. org/10.1210/me.2014-1154)

Xia Y, Shen S, Zhang X, Deng Z, Xiang Z, Wang H, Yi L, Gao Q \& Wang Y 2015 Epigenetic pattern changes in prenatal female Sprague-Dawley rats following exposure to androgen. Reproduction, Fertility, and Development 28 1414-1423. (https://doi.org/10.1071/RD14292)

Xu N, Azziz R \& Goodarzi MO 2010 Epigenetics in polycystic ovary syndrome: a pilot study of global DNA methylation. Fertility and Sterility 94 781.e1-783.e1. (https://doi.org/10.1016/j. fertnstert.2009.10.020)

$\mathrm{Xu}$ N, Chua AK, Jiang H, Liu NA \& Goodarzi MO 2014 Early embryonic androgen exposure induces transgenerational epigenetic and metabolic changes. Molecular Endocrinology 28 1329-1336. (https:// doi.org/10.1210/me.2014-1042)

Yan J, Li B, Lin B, Lee PT, Chung TH, Tan J, Bi C, Lee XT, Selvarajan V, $\mathrm{Ng}$ SB, et al. $2016 \mathrm{EZH} 2$ phosphorylation by JAK3 mediates a switch to noncanonical function in natural killer/T-cell lymphoma. Blood 128 948-958. (https://doi.org/10.1182/blood-2016-01-690701)

Yu C, Fan X, Sha QQ, Wang HH, Li BT, Dai XX, Shen L, Liu J, Wang L, Liu K, et al. 2017 CFP1 regulates histone H3K4 trimethylation and developmental potential in mouse oocytes. Cell Reports 20 1161-1172. (https://doi.org/10.1016/j.celrep.2017.07.011)

Zambrano E, Guzman C, Rodriguez-Gonzalez GL, Durand-Carbajal M \& Nathanielsz PW 2014 Fetal programming of sexual development and reproductive function. Molecular and Cellular Endocrinology 382 538-549. (https://doi.org/10.1016/j.mce.2013.09.008)

Zhang D, Cong J, Shen H, Wu Q \& Wu X 2014 Genome-wide identification of aberrantly methylated promoters in ovarian tissue of prenatally androgenized rats. Fertility and Sterility 102 1458-1467. (https://doi.org/10.1016/j.fertnstert.2014.07.1203)

Zhu JQ, Zhu L, Liang XW, Xing FQ, Schatten H \& Sun QY 2010 Demethylation of LHR in dehydroepiandrosterone-induced mouse model of polycystic ovary syndrome. Molecular Human Reproduction 16 260-266. (https://doi.org/10.1093/molehr/gap089)

Zhu R, Zhang JS, Zhu YZ, Fan J, Mao Y, Chen Q \& Zhu HG 2011 $\mathrm{HBx}$-induced androgen receptor expression in HBV-associated hepatocarcinoma is independent of the methylation status of its promoter. Histology and Histopathology 26 23-35. (https://doi. org/10.14670/HH-26.23)

Received in final form 4 February 2021

Accepted 24 March 2021

Accepted Manuscript published online 25 March 2021 https://joe.bioscientifica.com

https://doi.org/10.1530/JOE-20-0578 (c) 2021 Society for Endocrinology Published by Bioscientifica Ltd. Printed in Great Britain 